\title{
Lenalidomide in Diffuse Large B-Cell Lymphoma
}

\author{
Catherine Thieblemont, ${ }^{1}$ Marie-Hélène Delfau-Larue, ${ }^{2}$ and Bertrand Coiffier ${ }^{3}$ \\ ${ }^{1}$ Hematology and Oncology Department, Hôpital Saint-Louis, AP-HP and IUH, INSERM U728, University Paris VII, \\ 75010 Paris, France \\ ${ }^{2}$ Immunbiology Department, Groupe Hospitalier Henri Mondor-Albert Chenevier, AP-HP, 94000 Créteil, France \\ ${ }^{3}$ Hematology, Centre Hospitalier Lyon Sud, 69230 Pierre-Bénite, France
}

Correspondence should be addressed to Catherine Thieblemont, catherine.thieblemont@sls.aphp.fr

Received 1 March 2012; Accepted 22 August 2012

Academic Editor: Umberto Vitolo

Copyright (c) 2012 Catherine Thieblemont et al. This is an open access article distributed under the Creative Commons Attribution License, which permits unrestricted use, distribution, and reproduction in any medium, provided the original work is properly cited.

\begin{abstract}
Diffuse large B-cell lymphoma (DLBCL) is the most common form of non-Hodgkin's lymphoma (NHL) in adults. Even if the natural history of DLBCL has been improved with the advent of immunochemotherapy, the survival results obtained with current treatment options clearly indicate that new agents or novel approaches are needed. Lenalidomide (Revlimid, Celgene Corporation, Summit, NJ, USA), an analogue of thalidomide, is an immunomodulatory drug with pleiotropic mechanisms of action potentially adding to immunochemotherapy. We present here the biological rational for the use of lenalidomide in DLBCL in light of recent advances in the pathophysiology of the disease and the therapeutic results of the most recent trials published in literature or reported in meetings in relapsed/refractory situations as well as in first-line treatment.
\end{abstract}

\section{Introduction}

The incidence of non-Hodgkin's lymphoma (NHL) has been increasing worldwide during the last 40 years and accounts for $4 \%$ of all cancer diagnoses. Among the NHL, diffuse large B-cell lymphoma (DLBCL) is the most common form in adults, accounting for $25-30 \%$ of NHL cases [1] and is recognized as an entity since the first classification of NHL [2]. However, complexity and heterogeneity of the disease have been demonstrated over the past ten years, first by the most recent WHO classification including not less than 13 different subentities [3], and second by the biological analyses, particularly the gene expression profiling analyses dividing the disease in at least two molecular subgroups, that is, germinal center B-cell-like (GBC)- and activated B-cell-like (ABC)-DLBCL [4]. These biological analyses have been able not only to capture the molecular heterogeneity of tumor cells [4], but also to demonstrate the existence of a complex interaction between the tumor and its microenvironnement involving multiple signaling pathways and regulatory mechanisms [5].

Standard first-line treatment for DLBCL patients is based since 2002 on the association of rituximab and $\mathrm{CHOP}$ (cyclophosphamide, vincristine, doxorubicin, and prednisone) [6]. Even if the natural history of DLBCL has been improved with treatments based on this association, there is clearly a need of improvement of long-term results. With $\mathrm{R}-\mathrm{CHOP}$, the expected 5-year and 10-year OS rates are, respectively, $58 \%$ and $43.5 \%[7,8]$. To improve these results, several changes to conventional R-CHOP have emerged either in shortening intervals between cycles [9] or giving alternative regimens with intensified doses of chemotherapy [10]. R-EPOCH (etoposide doxorubicin, vincristine associated with bolus cyclophosphamide, prednisone) has demonstrated to give an OS rate of $73 \%$ [11]. In patients $<60$ years old, GELA has developed R-ACVBP (doxorubicin, cyclophosphamide, vindesine, bleomycin, prednisone) given every 14 days [10] and subsequently demonstrated a superiority of R-ACVBP compared to R-CHOP in several additional randomized studies $[12,13]$. However none of these intensified regimens are appropriate for patients with comorbidities or with older age, and the survival results obtained with these current treatment options for patients with DLBCL indicate that new treatment modalities are needed. 


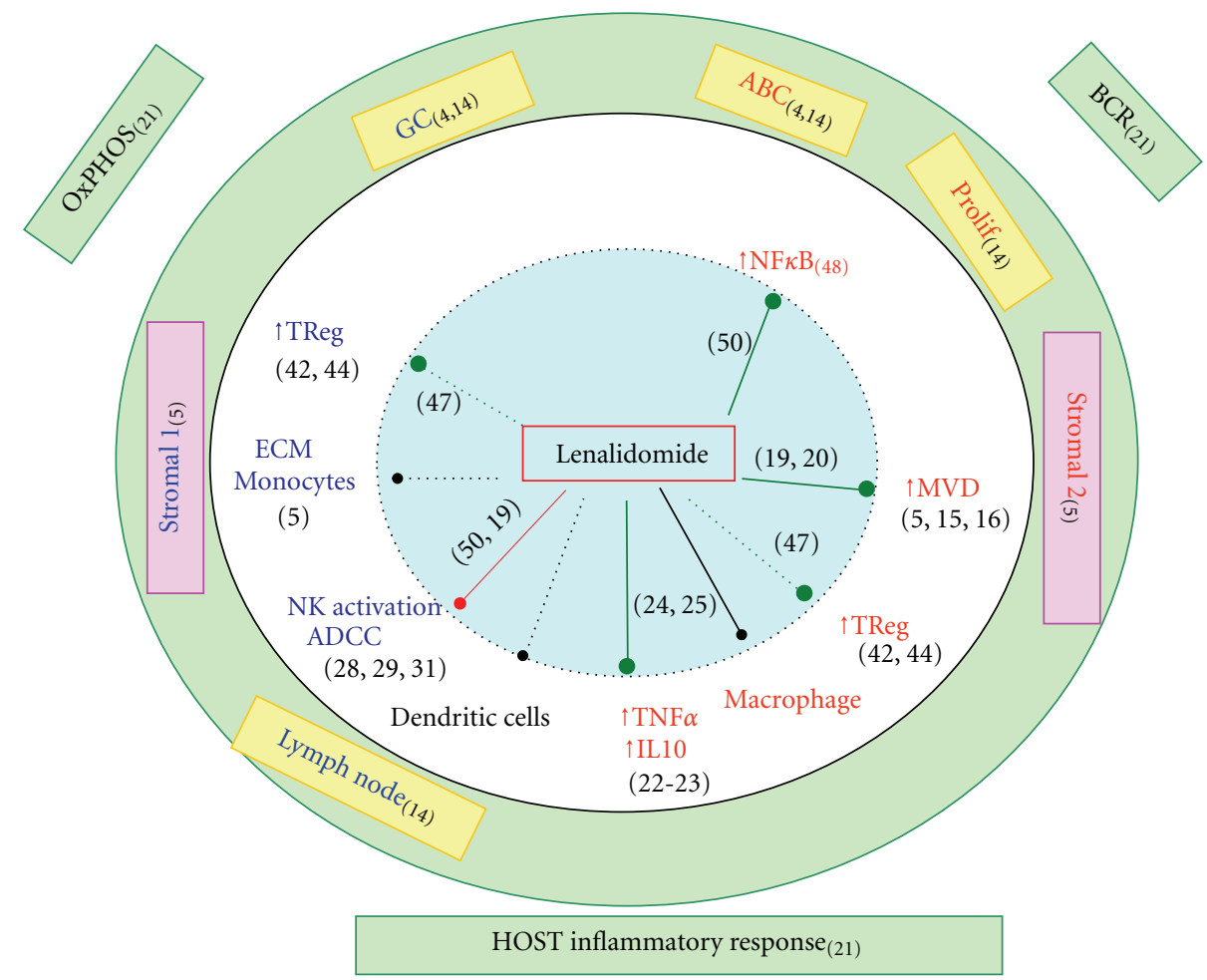

Figure 1: Biological effects of lenalidomide. Colored insets show the main transcriptomic signatures described in DLBCL. Just outside the circle are the signatures with prognostic impact. Inside the circle are indicated the factors studied in DLBCL, either with bad (red characters), good (blue), or undetermined (black) prognostic impact. Arrows indicate a negative (green), positive (red), or undetermined (black) regulation of lenalidomide on those factors in DLBCL. ECM: extracellular matrix components. MVD: microvascular density.

\section{Part I: Biological Relevance of Lenalidomide for the Treatment of DLBCL}

The antitumoral properties of lenalidomide in hematologic area (review in [14]) have been first studied in myeloma, and more recently in myelodysplastic syndromes and lymphomas, and can be grouped in 3 categories: (i) anti-angiogenesis, (ii) immune modulation, and (iii) direct tumor cell toxicities. Some progress on the understanding of DLBCL physiopathology enables us to speculate on biological pathways that could be targeted by lenalidomide (Figure 1).

2.1. Antiangiogenic Effects. Beside the two biologically and clinically distinct GC and ABC molecular subtypes of DLBCL defined by a tumoral cell signature $[4,15]$, different stromal gene signatures have been linked to prognosis $[5,15]$. One was associated with reduced survival, includes markers of endothelial cells, regulators of angiogenesis, and was shown to correlate with a quantitative measure of blood-vessel density (MVD) in tumor [5]. Unfavorable prognostic of high MVD has been confirmed on tissue microarray (TMA) in CHOP [16], and R-CHOP [17] treated DLBCL patients. Vascular endothelial growth factor (VEGF)-A is the most prominent proangiogenic factor and value of serum VEGF has prognosis impact in lymphomas (review in [18]). However, the pathogenic association of MVDs and VEGF expression by tumor cell in DLBCL remain controversial [19].
On the basis of these results and on results on in vivo model [20], it can be hypothesized that patients with DLBCL characterized by increased tumor MVD may benefit from antiangiogenic effect of lenalidomide [21].

\subsection{Effects on the Immune Microenvironment}

2.2.1. Action on Proinflammatory Cytokines and T-cell Activation. Using whole genome arrays, and multiple clustering methods, Monti and colleagues have identified 3 discrete subsets of DLBCL [22], including one characterized by increased expression of T-natural killer cell receptor and activation pathway components, complement cascade members, macrophage/dendritic cell markers, and inflammatory mediators which has been referred as "host response" (HR) signature. Consistent with the signature of an ongoing inflammatory/immune response, HR tumors had increased expression of interferon-induced genes, tumor necrosis family (TNF) ligands and receptors, cytokine receptors, adhesion molecules, and extracellular matrix components. The role of microenvironment associated cytokine in DLBCL physiopathology has been approached in another way. Host immune gene polymorphisms including TNF $\alpha$ and IL10 predict late survival in DLBCL patients in the prerituximab era [23]. In accordance, the combined elevation of both TNF $\alpha$ and IL-10 in sera of DLBCL patients at diagnosis has been shown to negatively impact on prognosis [24]. The effect 
of lenalidomide on TNF $\alpha$ production depends on immunological context. Lenalidomide has been shown to inhibit the production of proinflammatory cytokines including TNF $\alpha$ and to elevate the production of anti-inflammatory cytokine IL-10 from human PBMCs stimulated by LPS. In contrast, a strongly elevated production of $\mathrm{TNF} \alpha$ [25] by CD3 stimulated T-cell during costimulation by lenalidomide [26] has been reported. In this model, the augmentation of TNF $\alpha$ is due to production by both CD4+ and CD $8+\mathrm{T}$ cells, and is dependent on IL2-mediated signalling. Thus, depending on immune environment, lenalidomide could have differential impact on DLBCL tumors.

2.2.2. Action on NK Cells. Under normal circumstances of immune surveillance, human NK cells have inhibitory receptors that recognize MHC class I molecules as their cognate ligands on virtually every cell in the body [27] and activating receptors that sense stressed cells, that is, transformed or infected cells. Thus, NK cells spare healthy cells that express self-MHC class I molecules and low amounts of stressinduced self-molecules, whereas they selectively kill stressed target cells that downregulate MHC class I molecules and/or upregulate stress-induced self-molecules [28]. Investigating spontaneous B-cell lymphoma development in aging $\beta 2 \mathrm{~m}$ deficient mice, Street et al. [29] have shown that NK cells are critical in innate immune surveillance of B-cell lymphomas. In human, alteration of $\beta 2 \mathrm{~m}$ expression leading to an altered HLA-I staining patterns has been report in $40 / 53(75 \%)$ of DLBCL [30], a situation prone to activate NK cells. However, 75\% of such HLA-I deficient tumors have concomitant alterations of CD58 (LFA3) expression leading to a potential defect in adhesion and activation of NK cells as it has been shown for LFA1/ICAM1 [31]. The frequency of $\beta 2 \mathrm{~m}$ and CD58 expression defect was comparable in GCB and ABC DLBCL subgroups, but the correlation with the HR "Monti classification" has not been reported. We have previously shown that peripheral blood NK cell count deficiency was associated with lower response rate to $\mathrm{CHOP}$ like induction regiment [32] in DLBCL suggesting a cooperative contribution of the immune system to the chemotherapeutic response, a feature demonstrated in several mouse model [33]. In vitro addition of lenalidomide to PBMC of healthy individuals significantly increased their NK cell natural cytotoxicity (Davies et al., 2001 [34]) in a CD4+T cell and IL-2 dependent manner $[35,36]$. The in vivo effect of lenalidomide on NK cell of patients with DLBCL treated with lenalidomide is under study.

The introduction of rituximab in therapeutic arsenal has greatly changed the clinical course of DLBCL $[6,37,38]$. Beside natural cytotoxicity mentioned above, NK cell may be involved in Rituximab mediated antidody dependant cytotoxicity (ADCC) by the engagement of the Fc portion of the antibody on their Fc $\gamma$ RIII (CD16) receptors. It has been shown that Fc $\gamma$ RIII polymorphisms impact on antibody binding, resulting in more effective antibody-dependent cellular cytotoxicity in vitro [39]. The association with Fc $\gamma$ RIII polymorphisms and clinical outcome has been used to argue for an ADCC mechanism of action of rituximab in vivo, but the association is less significant in DLBCL [40] than initially report in follicular lymphoma [41].

Lenalidomide has been shown to enhance the NK-cellmediated ADCC and NK cell IFN- $\gamma$ production in a series of functional in vitro experiments using rituximab coated NHL cell lines, including one cell line derived from a DLBCL patient [42].

2.2.3. Action on Regulatory $T$ Cells. Regulatory $\mathrm{T}$ cells $\left(\mathrm{T}_{\mathrm{REG}}\right)$, defined as $\mathrm{CD} 4^{+} \mathrm{CD} 25^{+} \mathrm{T}$ cells, play an important role in the immune system, not only by inhibiting autoimmunity, but also by hampering the antitumour response [43]. In human NHL (including 6 DLBCL) it has been shown in vitro, that intratumoral $\mathrm{CD} 4^{+} \mathrm{CD} 25^{+}$cells can inhibit the proliferation of activated anti-tumour CTLs, and can inhibit the proliferation and the secretion of IFN $\gamma$ and IL4 by infiltrating CD4+CD25-T cells [44]. The expression of FOXP3 has been evaluated by immunohistochemical study on paraffin-embedded DLBCL tumor specimens and the number of FOXP3+ regulatory T cells has been first shown to be not predictive of clinical outcome [45]. However, the correlation between FOXP3+ infiltrating $\mathrm{T}$ cells and prognosis has been subsequently evaluated independently in GC and non-GC DLBCL subgroups [46], as defined by Hans algorithm [47]. Despite the fact that the absolute FOXP3+ cell numbers were similar in GC and non-GC DLBCL, a high amount of tumor-infiltrating FOXP3+ cells was of good prognostic value (DFS) in GC but was associated with an adverse clinical outcome in non-GC subgroup. In this study, localization of FOXP3 + cells within tumor, a feature that has been shown to impact their clinical value in solid tumor [48], has not been evaluated.

Lenalidomide can inhibit the proliferation of FOXP3+ CTLA4+CD4+CD25 $5^{\text {high }} \mathrm{T}_{\text {REG }}$ cells in healthy donor PBMCs cultured for 7 days with IL-2 [49]. Moreover, lenalidomide inhibit the suppressor function of the $\mathrm{T}_{\text {REG }}$ cells against autologous responder cells in vitro. This inhibitory activity is associated with reduction of FOXP3 and OX40 expression. However, to our knowledge, nothing has been report on the effect of lenalidomide on $T_{R E G}$ extracted from DLBCL tumor samples.

2.3. Direct Effect on Tumor Cells. A hallmark of ABC DLBCL is the constitutive activation of the $\mathrm{NF} \kappa \mathrm{B}$ pathway, on which they rely for survival and proliferation [34]. NF $\kappa$ B activation in mediated through oncogenic driver mutations affecting Bcell receptor-NFK $\mathrm{B}$ signaling (review in [50]). Beside effects on microenvironment, lenalidomide has been shown to have a direct effect on DLBCL cell lines, with a decrease in $\mathrm{NF} \kappa \mathrm{B}$ activity and an arrest in DNA synthesis [51].

\section{Part II: Lenalidomide and Treatment of DLBCL}

3.1. Response to Lenalidomide in Relapsed/Refractory DLBCL. Data emerging from early clinical trials demonstrated that lenalidomide has a significant activity against relapsed/ refractory DLBCL either as monotherapy or as an association with rituximab. Published results are shown in Table 1. 
TABLE 1: Response to Lenalidomide in relapsed/refractory diffuse large B-cell lymphomas.

\begin{tabular}{|c|c|c|c|c|}
\hline \multirow{2}{*}{$\begin{array}{l}\text { Lenalidomide } \\
\text { Name of the protocol }\end{array}$} & \multicolumn{2}{|c|}{ Monotherapy } & \multirow{2}{*}{\multicolumn{2}{|c|}{$\begin{array}{c}\text { Association } \\
\text { Lenalidomide and rituximab [54] }\end{array}$}} \\
\hline & NHL002 [52] & NHL003 [53] & & \\
\hline Year of publication & 2008 & 2011 & \multicolumn{2}{|r|}{2011} \\
\hline Type of study & Multicentric & International & \multicolumn{2}{|c|}{ Multicentric } \\
\hline Phase & Phase II & Phase II & \multicolumn{2}{|c|}{ Phase II } \\
\hline Treatment & Lenalidomide & Lenalidomide & \multicolumn{2}{|c|}{ Lenalidomide and rituximab } \\
\hline Dose of lenalidomide: & $\begin{array}{c}25 \mathrm{mg} / \mathrm{d}, \mathrm{D} 1-21 \\
\text { every } 28 \text { days }\end{array}$ & $\begin{array}{c}25 \mathrm{mg} / \mathrm{d}, \mathrm{D} 1-21 \\
\text { every } 28 \text { days }\end{array}$ & \multicolumn{2}{|c|}{$\begin{array}{c}20 \mathrm{mg} / \mathrm{d}, \mathrm{D} 1-21 \\
\text { every } 28 \text { days }\end{array}$} \\
\hline $\begin{array}{l}\text { Duration or treatment or } \\
\text { No. of cycles }\end{array}$ & 52 weeks & - & \multicolumn{2}{|c|}{4 cycles + maintenance $(n=10$ pts $)$} \\
\hline No. of patients & 49 & 267 & \multicolumn{2}{|r|}{23} \\
\hline No. of DLBCL & 26 & 108 & \\
\hline Response* & & & \multicolumn{2}{|r|}{$\begin{array}{l}23 \\
\text { Complete therapy }\end{array}$} \\
\hline ORR $n,(\%)$ & $5(19)$ & $30(28)$ & $8(35)$ & $8(35)$ \\
\hline $\mathrm{CR} n,(\%)$ & $1(3)$ & $8(7)$ & $7(31)$ & $8(35)$ \\
\hline CRU $n,(\%)$ & $2(8)$ & - & \multicolumn{2}{|r|}{-} \\
\hline $\mathrm{PR} n,(\%)$ & $2(8)$ & $22(20)$ & $1(4)$ & $0(0)$ \\
\hline Stable disease $n,(\%)$ & $7(27)$ & $23(21)$ & $2(8)$ & $2(8)$ \\
\hline Progression $n,(\%)$ & $14(54)$ & $40(37)$ & \multicolumn{2}{|r|}{$13(57)$} \\
\hline Followup & & 9.2 & \multicolumn{2}{|r|}{16} \\
\hline Median time to response (month) & $\begin{array}{l}\text { PR: } 1.9(1.2-3.7) \\
\text { CR: } 4.3(1.9-10.5)\end{array}$ & $1.9(1.4-11.5)$ & \multicolumn{2}{|r|}{ - } \\
\hline Median response duration (month) & $6.2(0-12.8)$ & 1.6 & \multicolumn{2}{|r|}{-} \\
\hline PFS, Median (month) & 4 & 2.7 & \multicolumn{2}{|c|}{1 -year DFS 34.8\% } \\
\hline
\end{tabular}

ORR: overall response rate, CR: complete response, CRU: complete response unconfirmed, PR: partial response, PFS: progression free survival.

NHL002: the results of response are specifically reported for DLBCL.

NHL003: the results of response are specifically reported for DLBCL.

The first phase II trial was a single-arm, multicenter trial (NHL002) that evaluates the safety and efficacy of lenalidomide oral monotherapy $(25 \mathrm{mg} /$ day during 21 days every 28 days) in 49 patients with relapsed or refractory aggressive NHL [52]. Among them, 26 patients presented a relapsed/refractory DLBCL. The median age was 65 years. All these patients were heavily pretreated with a median of four prior treatment regimens. Overall response rate (ORR) was $19 \%(n=5 / 26)$, including 3 complete responses (CRU + $\mathrm{CR}$ ) and 2 partial responses (PR).

An international phase II study (NHL003) was then conducted enrolling 218 patients with refractory/relapsed B-cell aggressive lymphoma, and confirmed the efficacy of lenalidomide in this category of patients [53]. One hundred and eight patients with diffuse large B-cell lymphoma were included. As the previous study, the treatment consisted in lenalidomide $25 \mathrm{mg}$ orally once daily on days 1-21 of every 28 day cycle. Thirty patients $(28 \%)$ exhibited an objective response ( $8 \mathrm{CR}$, and $22 \mathrm{PR}$ ). Interestingly, response to lenalidomide therapy was independent of the tumor burden, and of the number and the type of prior treatment. Compared to other type of lymphomas included (mantle cell lymphoma, transformed large B-cell lymphoma, follicular lymphoma, grade III), progression-free survival (PFS) of the patients with DLBCL was the shortest.

In contrast, patients with large cell NHL of the transformed type $(n=33)$ had substantially better results
TABLE 2: Grade III-IV toxicities with lenalidomide as monotherapy in relapsed/refractory DLBCL.

\begin{tabular}{lcc}
\hline & NHL002 [52] & NHL003 [53] \\
& $\%$ & $\%$ \\
\hline Neutropenia & 33 & 41 \\
Febrile neutropenia & 6.1 & 2.3 \\
Thrombocytopenia & 20.4 & 18.4 \\
Anemia & 6.1 & 9.2 \\
Fatigue & 6.1 & 4.6 \\
Deep vein thrombosis & 2 & 2.3 \\
Neuropathy & 0 & 0 \\
\hline
\end{tabular}

[53]. Median PFS was of 5.1 months and median response duration of 12.8 months. These results were further explored in a study analysing 33 patients with transformed follicular lymphoma (tFL), transformed chronic lymphocytic leukaemia/small lymphocytic lymphoma (tCLL/SLL) [55]. Lenalidomide was administered at the same dosage. Among patients with tFL, ORR was $57 \%$, with a median response duration of 12.8 months. None of the patients with tCLL/SLL responded to lenalidomide monotherapy.

These encouraging results are confirmed in a retrospective study (REVEAL study) showing an objective response rate after 3 cycles at $69.2 \%$ in heavily pretreated patients with relapsed LNH [59]. 
TABLE 3: Response to lenalidomide in patients with diffuse large B-cell lymphoma in first-line treatment.

\begin{tabular}{|c|c|c|c|}
\hline Name of the protocol & R2-CHOP [56] & LR-CHOP21 [57] & R2-CHOP [58] \\
\hline Year of publication & 2011 & 2010 & 2011 \\
\hline Type of study & Monocentric & Multicentric-IIL & Multicentric \\
\hline Phase & Phase I & Phase I-II & Phase I-II \\
\hline Treatment & Lenalidomide and R-CHOP21 & Lenalidomide and R-CHOP21 & Lenalidomideand R-CHOP21 \\
\hline Dose of lenalidomide: & $\begin{array}{c}15 \text { to } 25 \mathrm{mg} / \mathrm{d}, \mathrm{D} 1-10 \\
\text { every } 21 \text { days }\end{array}$ & $\begin{array}{c}5 \text { to } 20 \mathrm{mg} / \mathrm{d}, \mathrm{D} 1-14 \\
\text { every } 21 \text { days }\end{array}$ & $\begin{array}{c}5 \text { to } 25 \mathrm{mg} / \mathrm{d}, \mathrm{D} 1-14 \\
\text { every } 21 \text { days }\end{array}$ \\
\hline No. of cycles & 6 & 6 & 6 \\
\hline $\begin{array}{l}\text { No. of patients } \\
\text { with DLBCL }\end{array}$ & 24 & 21 & 27 \\
\hline $\begin{array}{l}\text { Recommended dose } \\
\text { in function of DLT }\end{array}$ & $25 \mathrm{mg}$ & $15 \mathrm{mg}$ & $25 \mathrm{mg}$ \\
\hline \multicolumn{4}{|l|}{ Toxicity } \\
\hline Hematologic & Grade III-IV & Grade III-IV & Grade III-IV \\
\hline Anemia & $21 \%$ & $4 \%$ & - \\
\hline Neutropenia & $88 \%$ & $28 \%$ & $59 \%$ \\
\hline \multirow[t]{2}{*}{ Thrombocytopenia } & $29 \%$ & $10 \%$ & $30 \%$ \\
\hline & Grade III & Grade III & Grade I-II \\
\hline Peripheral neurotoxicity & $8 \%$ & $14 \%$ & $48 \%$ \\
\hline Vascular thrombosis & $8 \%$ & & $7 \%$ \\
\hline \multicolumn{4}{|l|}{ Response } \\
\hline ORR $n,(\%)$ & $22(87.5)$ & $16(72)$ & $27(100)$ \\
\hline $\mathrm{CR} n,(\%)$ & $18(77)$ & $15(71)$ & $20(74)$ \\
\hline $\mathrm{PR} n,(\%)$ & & $1(5)$ & $7(26)$ \\
\hline Stable disease $n,(\%)$ & & & - \\
\hline Progression $n,(\%)$ & $5(21)$ & $5(16)$ & - \\
\hline
\end{tabular}

When associated to rituximab, results of ORR seems equivalent to lenalidomide alone, with an ORR of $35 \%$ [54]. However number of CR seems higher as almost all but one responding patients were in CR. In this trial, the treatment plan comprised an induction phase with lenalidomide $(20 \mathrm{mg} / \mathrm{day}, \mathrm{D} 1-\mathrm{D} 21$ of a 28 -day cycle for 4 cycles) and rituximab $(375 \mathrm{mg} / \mathrm{m} 2$ on day 1 and day 21 of each cycle-total of 4 cycles) and maintenance therapy proposed to the responders (CR, PR SD) with lenalidomide. Interestingly one patient in $\mathrm{PR}$ after induction converted to $\mathrm{CR}$ during the maintenance.

Interestingly maintenance with lenalidomide is currently tested in patients with relapsed DLBCL who achieved at least a partial response to second-line chemotherapy (ICE, DHAP/DHAOx, or MINE regimen) and rituximab at the dose of $25 \mathrm{mg}$ once daily for 21 days out of 28 until progression (NCT00799513).

3.2. Toxicity of Lenalidomide Alone in DLBCL. When lenalidomide is used in monotherapy at the "standard" dose of $25 \mathrm{mg} / \mathrm{d}$ D1-D21 cycling at 28 days, the most common grade 3 and 4 adverse events are neutropenia occurring in 33\% to $41 \%$ of the patients, and thrombocytopenia in $20 \%$ of the patients. The neutropenia was rarely complicated with a febrile neutropenia, reported in $2-6 \%$ of the patients. No neuropathy was reported. Deep vein thrombosis was described in $2 \%$ of the patients. Other grade III-IV toxicities were anemia $(<10 \%)$ and asthenia in $5 \%$ of the patients. These toxicities required a dose reduction in one third of the patients in both trials $[52,53]$ (Table 2). The median time to first dose reduction or interruption of treatment was 33 days [53]. The most common reasons for dose reduction were neutropenia (56\%) and thrombocytopenia (31\%) [53].

3.3. Lenalidomide in First-Line Treatment in DLBCL. Combination of lenalidomide and standard R-CHOP21 have been recently published or reported in meetings by several groups in phase I-II [56]. This strategy of "R2-CHOP" was proposed to patients in first-line treatment (Table 3). The lenalidomide dose levels tested were between $5 \mathrm{mg}$ up to $25 \mathrm{mg}$ /day. Duration of treatment by cycle was between 10 days to 14 days. Dose limiting toxicity principally occurred because of haematological toxicity described as the most frequent adverse event. Grade III-IV neutropenia occurred in $28 \%$ to $88 \%$ of the patients, and Grade III-IV thrombocytopenia in 10 to $30 \%$ of the patients. Grade I-II neuropathy was 
observed in half of the patients, and grade III-IV in around $10 \%$ of the patients.

Beside concomitant association of lenalidomide and Rchemotherapy, alternative way to administer lenalidomide in front-line is a strategy of maintenance therapy after an induction of R-CHOP. Lenalidomide seems attractive to test in maintenance with several positive arguments. It is an oral drug, easy to administer. The early antitumoral efficacy and immunomodulatory effect have been shown, and finally tolerance is acceptable. This strategy is currently investigated in an international trial conducted by the LYSA (EUDRACT Number: 2008-008202-52), where lenalidomide is proposed in maintenance after R-CHOP21 or R-CHOP14 in responding patients $(\mathrm{CR}+\mathrm{PR})[60]$ aged from 60 to 80 years old with at least one adverse IPI prognostic factors.

3.4. Cell of Origin and Response to Lenalidomide. Based on the biological rational of Lenalidomide and the new categorization of DLBCL [4], Hernandez-Ilizaliturri et al., recently reported the response to lenalidomide in relapsed/refractory DLBCL in analyzing them within their subgroups: germinal center B-cell (GCB-)-like- or nongerminal center B-cell (non-GCB-)like- DLBCL [61]. Forty patients were retrospectively analyzed using the Hans's algorithm based on the expression of CD10, BCL6, and IRF4/MUM1 by immunohistochemistry [47]. Twenty-three were classified as GCB-like DLBCL and 17 as non-GCB-like DLBCL. Differences were observed in responses rates, PFS and OS. ORR rate was significantly higher in patients with non-GCBlike DLBCL compared to patients with GCB-like DLBCL (OOR rates, 53\% versus 9\%, $P=.006$ ). Complete response rate was 23.5 versus $4.3 \%$. Median progression-free survival was 6.2 months versus 1.7 months. No difference in OS was yet observed.

\section{Conclusion}

Lenalidomide is a promising drug in DLBCL in relapse as well as in front-line therapy. Several trials have reported interesting results in monotherapy as well as in association with rituximab alone or with immunochemotherapy. Tolerance seems acceptable and long term results of the recently published trials should in the future help to define the place of this drug in the therapeutic strategy of patients with DLBCL. Numerous new therapeutic molecules are under development or in phase I/II evaluation and some additional biological works are necessary to decipher the precise mechanism of action of lenalidomide in DLBCL subgroups in order to develop rational combinations [62].

\section{Authors' Contribution}

C. Thieblemont and M.-H. Delfau-Larue have contributed equally to this paper.

\section{References}

[1] The Non-Hodgkin's Lymphoma Classification Project, "A clinical evaluation of the International Lymphoma Study
Group classification of non-Hodgkin's lymphoma," Blood, vol. 89, no. 11, pp. 3909-3918, 1997.

[2] C. Percy, G. O'Conor, L. G. Ries, and E. S. Jaffe, "NonHodgkin's lymphomas. Application of the international classification of diseases for oncology (ICD-O) to the working formulation," Cancer, vol. 54, no. 7, pp. 1435-1438, 1984.

[3] S. H. Swerdlow, E. Campo, N. L. Harris et al., WHO Classification of Tumours of Haematopoietic and Lymphoid Tissues, IARC Press, Lyon, France, 2008.

[4] A. A. Alizadeh, M. B. Elsen, R. E. Davis et al., "Distinct types of diffuse large B-cell lymphoma identified by gene expression profiling," Nature, vol. 403, no. 6769, pp. 503-511, 2000.

[5] G. Lenz, G. Wright, S. S. Dave et al., "Stromal gene signatures in large-B-cell lymphomas," New England Journal of Medicine, vol. 359, no. 22, pp. 2313-2323, 2008.

[6] B. Coiffier, E. Lepage, J. Brière et al., "Chop chemotherapy plus rituximab compared with chop alone in elderly patients with diffuse large-B-cell lymphoma," New England Journal of Medicine, vol. 346, no. 4, pp. 235-242, 2002.

[7] P. Feugier, A. van Hoof, C. Sebban et al., "Long-term results of the R-CHOP study in the treatment of elderly patients with diffuse large B-cell lymphoma: a study by the groupe d'etude des lymphomes de l'adulte," Journal of Clinical Oncology, vol. 23, no. 18, pp. 4117-4126, 2005.

[8] B. Coiffier, C. Thieblemont, E. van den Neste et al., "Longterm outcome of patients in the LNH-98.5 trial, the first randomized study comparing rituximab-CHOP to standard CHOP chemotherapy in DLBCL patients: a study by the Groupe d'Etudes des Lymphomes de l'Adulte," Blood, vol. 116, no. 12, pp. 2040-2045, 2010.

[9] W. Klapper, H. Stoecklein, S. Zeynalova et al., "Structural aberrations affecting the MYC locus indicate a poor prognosis independent of clinical risk factors in diffuse large B-cell lymphomas treated within randomized trials of the German HighGrade Non-Hodgkin's Lymphoma Study Group (DSHNHL)," Leukemia, vol. 22, no. 12, pp. 2226-2229, 2008.

[10] H. Tilly, E. Lepage, B. Coiffier et al., "Intensive conventional chemotherapy (ACVBP regimen) compared with standard $\mathrm{CHOP}$ for poor-prognosis aggressive non-Hodgkin lymphoma," Blood, vol. 102, no. 13, pp. 4284-4289, 2003.

[11] W. H. Wilson, K. Dunleavy, S. Pittaluga et al., "Phase II study of dose-adjusted EPOCH and rituximab in untreated diffuse large B-cell lymphoma with analysis of germinal center and post-germinal center biomarkers," Journal of Clinical Oncology, vol. 26, no. 16, pp. 2717-2724, 2008.

[12] C. Récher, B. Coiffier, C. Haioun et al., "Intensified chemotherapy with ACVBP plus rituximab versus standard $\mathrm{CHOP}$ plus rituximab for the treatment of diffuse large B-cell lymphoma (LNH03-2B): an open-label randomised phase 3 trial," The Lancet, vol. 378, no. 9806, pp. 1858-1867, 2011.

[13] F. Reyes, E. Lepage, G. Ganem et al., "ACVBP versus CHOP plus radiotherapy for localized aggressive lymphoma," New England Journal of Medicine, vol. 352, no. 12, pp. 1197-1205, 2005.

[14] J. B. Bartlett, K. Dredge, and A. G. Dalgleish, "The evolution of thalidomide and its IMiD derivatives as anticancer agents," Nature Reviews Cancer, vol. 4, no. 4, pp. 314-322, 2004.

[15] A. Rosenwald, G. Wright, W. C. Chan et al., "The use of molecular profiling to predict survival after chemotherapy for diffuse large-B-cell lymphoma," New England Journal of Medicine, vol. 346, no. 25, pp. 1937-1947, 2002.

[16] D. Gratzinger, S. Zhao, R. J. Tibshirani et al., "Prognostic significance of VEGF, VEGF receptors, and microvessel density 
in diffuse large B cell lymphoma treated with anthracyclinebased chemotherapy," Laboratory Investigation, vol. 88, no. 1, pp. 38-47, 2008.

[17] T. M. Cardesa-Salzmann, L. Colomo, G. Gutierrez et al., "High microvessel density determines a poor outcome in patients with diffuse large B-cell lymphoma treated with rituximab plus chemotherapy," Haematologica, vol. 96, no. 7, pp. 996$1001,2011$.

[18] A. Koster and J. M. M. Raemaekers, "Angiogenesis in malignant lymphoma," Current Opinion in Oncology, vol. 17, no. 6, pp. 611-616, 2005.

[19] J. Ruan, K. Hajjar, S. Rafii, and J. P. Leonard, "Angiogenesis and antiangiogenic therapy in non-Hodgkin's lymphoma," Annals of Oncology, vol. 20, no. 3, pp. 413-424, 2009.

[20] N. Reddy, F. J. Hernandez-Ilizaliturri, G. Deeb et al., "Immunomodulatory drugs stimulate natural killer-cell function, alter cytokine production by dendritic cells, and inhibit angiogenesis enhancing the anti-tumour activity of rituximab in vivo," British Journal of Haematology, vol. 140, no. 1, pp. 36-45, 2008.

[21] L. Lu, F. Payvandi, L. Wu et al., "The anti-cancer drug lenalidomide inhibits angiogenesis and metastasis via multiple inhibitory effects on endothelial cell function in normoxic and hypoxic conditions," Microvascular Research, vol. 77, no. 2, pp. 78-86, 2009.

[22] S. Monti, K. J. Savage, J. L. Kutok et al., "Molecular profiling of diffuse large B-cell lymphoma identifies robust subtypes including one characterized by host inflammatory response," Blood, vol. 105, no. 5, pp. 1851-1861, 2005.

[23] T. M. Habermann, S. S. Wang, M. J. Maurer et al., "Host immune gene polymorphisms in combination with clinical and demographic factors predict late survival in diffuse large B-cell lymphoma patients in the pre-rituximab era," Blood, vol. 112, no. 7, pp. 2694-2702, 2008.

[24] E. Lech-Maranda, J. Bienvenu, F. Broussais-Guillaumot et al., "Plasma TNF- $\alpha$ and IL-10 level-based prognostic model predicts outcome of patients with diffuse large B-cell lymphoma in different risk groups defined by the international prognostic index," Archivum Immunologiae et Therapiae Experimentalis, vol. 58, no. 2, pp. 131-141, 2010.

[25] L. G. Corral, P. A. J. Haslett, G. W. Muller et al., "Differential cytokine modulation and $\mathrm{T}$ cell activation by two distinct classes of thalidomide analogues that are potent inhibitors of TNF- $\alpha$, Journal of Immunology, vol. 163, no. 1, pp. 380-386, 1999.

[26] J. B. Marriott, I. A. Clarke, K. Dredge, G. Muller, D. Stirling, and A. G. Dalgleish, "Thalidomide and its analogues have distinct and opposing effects on TNF- $\alpha$ and TNFR2 during co-stimulation of both $\mathrm{CD}^{+}$and $\mathrm{CD}^{+}{ }^{+} \mathrm{T}$ cells," Clinical and Experimental Immunology, vol. 130, no. 1, pp. 75-84, 2002.

[27] M. A. Caligiuri, "Human natural killer cells," Blood, vol. 112, no. 3, pp. 461-469, 2008.

[28] E. Vivier, E. Tomasello, M. Baratin, T. Walzer, and S. Ugolini, "Functions of natural killer cells," Nature Immunology, vol. 9, no. 5, pp. 503-510, 2008.

[29] S. E. A. Street, Y. Hayakawa, Y. Zhan et al., "Innate immune surveillance of spontaneous B cell lymphomas by natural killer cells and $\gamma \delta$ T cells," Journal of Experimental Medicine, vol. 199, no. 6, pp. 879-884, 2004.

[30] M. Challa-Malladi, Y. K. Lieu, O. Califano et al., "Combined genetic inactivation of $\beta 2$-microglobulin and CD58 reveals frequent escape from immune recognition in diffuse large $B$ cell lymphoma," Cancer Cell, vol. 20, no. 6, pp. 728-740, 2011.
[31] D. F. Barber, M. Faure, and E. O. Long, "LFA-1 contributes an early signal for NK cell cytotoxicity," Journal of Immunology, vol. 173, no. 6, pp. 3653-3659, 2004.

[32] A. Plonquet, C. Haioun, J. P. Jais et al., "Peripheral blood natural killer cell count is associated with clinical outcome in patients with aaIPI 2-3 diffuse large B-cell lymphoma," Annals of Oncology, vol. 18, no. 7, pp. 1209-1215, 2007.

[33] L. Zitvogel, O. Kepp, and G. Kroemer, "Immune parameters affecting the efficacy of chemotherapeutic regimens," Nature Reviews Clinical Oncology, vol. 8, no. 3, pp. 151-160, 2011.

[34] R. E. Davis, K. D. Brown, U. Siebenlist, and L. M. Staudt, "Constitutive nuclear factor $\kappa \mathrm{B}$ activity is required for survival of activated B cell-like diffuse large B cell lymphoma cells," Journal of Experimental Medicine, vol. 194, no. 12, pp. 18611874, 2001.

[35] T. Hayashi, T. Hideshima, M. Akiyama et al., "Molecular mechanisms whereby immunomodulatory drugs activate natural killer cells: clinical application," British Journal of Haematology, vol. 128, no. 2, pp. 192-203, 2005.

[36] A. K. Hsu, H. Quach, T. Tai et al., "The immunostimulatory effect of lenalidomide on NK-cell function is profoundly inhibited by concurrent dexamethasone therapy," Blood, vol. 117, no. 5, pp. 1605-1613, 2011.

[37] T. M. Habermann, E. A. Weller, V. A. Morrison et al., "Rituximab-CHOP versus CHOP alone or with maintenance rituximab in older patients with diffuse large B-cell lymphoma," Journal of Clinical Oncology, vol. 24, no. 19, pp. 31213127, 2006.

[38] M. Pfreundschuh, L. Trümper, A. Österborg et al., "CHOP-like chemotherapy plus rituximab versus CHOP-like chemotherapy alone in young patients with good-prognosis diffuse large-B-cell lymphoma: a randomised controlled trial by the MabThera International Trial (MInT) Group," Lancet Oncology, vol. 7, no. 5, pp. 379-391, 2006.

[39] S. Dall'Ozzo, S. Tartas, G. Paintaud et al., "Rituximabdependent cytotoxicity by natural killer cells: influence of FCGR3A polymorphism on the concentration-effect relationship," Cancer Research, vol. 64, no. 13, pp. 4664-4669, 2004.

[40] M. Ahlgrimm, M. Pfreundschuh, M. Kreuz, E. Regitz, K.D. Preuss, and J. Bittenbring, "The impact of Fc- $\gamma$ receptor polymorphisms in elderly patients with diffuse large B-cell lymphoma treated with CHOP with or without rituximab," Blood, vol. 118, no. 17, pp. 4657-4662, 2011.

[41] G. Cartron, L. Dacheux, G. Salles et al., "Therapeutic activity of humanized anti-CD20 monoclonal antibody and polymorphism in IgG Fc receptor FcyrIIIa gene," Blood, vol. 99, no. 3, pp. 754-758, 2002.

[42] L. Wu, M. Adams, T. Carter et al., "Lenalidomide enhances natural killer cell and monocyte-mediated antibodydependent cellular cytotoxicity of rituximab-treated CD20 tumor cells," Clinical Cancer Research, vol. 14, no. 14, pp. 4650-4657, 2008.

[43] T. Yamaguchi and S. Sakaguchi, "Regulatory T cells in immune surveillance and treatment of cancer," Seminars in Cancer Biology, vol. 16, no. 2, pp. 115-123, 2006.

[44] Z. Z. Yang, A. J. Novak, M. J. Stenson, T. E. Witzig, and S. M. Ansell, "Intratumoral $\mathrm{CD} 4{ }^{+} \mathrm{CD} 25^{+}$regulatory T-cellmediated suppression of infiltrating $\mathrm{CD} 4^{+} \mathrm{T}$ cells in B-cell non-Hodgkin lymphoma," Blood, vol. 107, no. 9, pp. 36393646, 2006.

[45] S. Hasselblom, M. Sigurdadottir, U. Hansson, H. NilssonEhle, B. Ridell, and P. O. Andersson, "The number of tumour-infiltrating TIA- ${ }^{+}$cytotoxic T cells but not FOXP3 ${ }^{+}$ 
regulatory $\mathrm{T}$ cells predicts outcome in diffuse large B-cell lymphoma," British Journal of Haematology, vol. 137, no. 4, pp. 364-373, 2007.

[46] A. Tzankov, C. Meier, P. Hirschmann, P. Went, S. A. Pileri, and S. Dirnhofer, "Correlation of high numbers of intratumoral $\mathrm{FOXP}^{+}$regulatory $\mathrm{T}$ cells with improved survival in germinal center-like diffuse large B-cell lymphoma, follicular lymphoma and classical Hodgkin's lymphoma," Haematologica, vol. 93, no. 2, pp. 193-200, 2008.

[47] C. P. Hans, D. D. Weisenburger, T. C. Greiner et al., "Confirmation of the molecular classification of diffuse large B-cell lymphoma by immunohistochemistry using a tissue microarray," Blood, vol. 103, no. 1, pp. 275-282, 2004.

[48] C. Ménétrier-Caux, M. Gobert, and C. Caux, "Differences in tumor regulatory $\mathrm{T}$-cell localization and activation status impact patient outcome," Cancer Research, vol. 69, no. 20, pp. 7895-7898, 2009.

[49] C. Galustian, B. Meyer, M. C. Labarthe et al., "The anticancer agents lenalidomide and pomalidomide inhibit the proliferation and function of T regulatory cells," Cancer Immunology, Immunotherapy, vol. 58, no. 7, pp. 1033-1045, 2009.

[50] A. L. Shaffer III, R. M. Young, and L. M. Staudt, "Pathogenesis of human B cell lymphomas," Annual Review of Immunology, vol. 30, pp. 565-610, 2012.

[51] F. J. Hernandez-Ilizaliturri, N. Reddy, B. Holkova, E. Ottman, and M. S. Czuczman, "Immunomodulatory drug CC-5013 or CC-4047 and rituximab enhance antitumor activity in a severe combined immunodeficient mouse lymphoma model," Clinical Cancer Research, vol. 11, no. 16, pp. 5984-5992, 2005.

[52] P. H. Wiernik, I. S. Lossos, J. M. Tuscano et al., "Lenalidomide monotherapy in relapsed or refractory aggressive nonHodgkin's lymphoma," Journal of Clinical Oncology, vol. 26, no. 30, pp. 4952-4957, 2008.

[53] T. E. Witzig, J. M. Vose, P. L. Zinzani et al., "An international phase II trial of single-agent lenalidomide for relapsed or refractory aggressive B-cell non-Hodgkin's lymphoma," Annals of Oncology, vol. 22, no. 7, pp. 1622-1627, 2011.

[54] P. L. Zinzani, C. Pellegrini, L. Gandolfi et al., "Combination of lenalidomide and rituximab in elderly patients with relapsed or refractory diffuse large B-cell lymphoma: a phase 2 trial," Clinical Lymphoma, Myeloma and Leukemia, vol. 11, no. 6, pp. 462-466, 2011.

[55] M. S. Czuczman, J. M. Vose, T. E. Witzig et al., “The differential effect of lenalidomide monotherapy in patients with relapsed or refractory transformed non-Hodgkin lymphoma of distinct histological origin," British Journal of Haematology, vol. 154, no. 4, pp. 477-481, 2011.

[56] G. S. Nowakowski, B. LaPlant, T. M. Habermann et al., "Lenalidomide can be safely combined with R-CHOP (R2CHOP) in the initial chemotherapy for aggressive B-cell lymphomas: phase I study," Leukemia, vol. 25, pp. 1877-1881, 2011.

[57] U. Vitolo, A. Chiappella, A. Carella et al., "Prospective, multicenter phase I-II pilot trial to evaluate efficacy and safety of lenalidomide plus rituximab-CHOP21 (LR-CHOP21) for elderly patients with untreated diffuse large B-Cell lymphoma (DLBCL): interim analysis of the intergruppo italiano linfomi (IIL) REAL07 study," Blood, vol. 116, p. 2871, 2010, ASH Annual Meeting Abstracts.

[58] H. Tilly, F. Morschhauser, G. Salles et al., "Phase I study of escalating doses of lenalidomide combined with R-CHOP
(R2-CHOP) for front-line treatment of B-Cell lymphomas," Blood, vol. 118, p. 1632, 2011, ASH Annual Meeting Abstracts.

[59] L. Rigacci, F. Zaja, A. Fabbri et al., "Lenalidomide administration in heavily pretreated patients with non hodgkin lymphoma-first report of the REVEAL study (REVlimid effectiveness of administration in patients with lymphoma)," Blood, vol. 118, 2011, ASH Annual Meeting Abstracts, Abstract 4979.

[60] B. D. Cheson, B. Pfistner, M. E. Juweid et al., "Revised response criteria for malignant lymphoma," Journal of Clinical Oncology, vol. 25, no. 5, pp. 579-586, 2007.

[61] F. J. Hernandez-Ilizaliturri, G. Deeb, P. L. Zinzani et al., "Higher response to lenalidomide in relapsed/refractory diffuse large b-cell lymphoma in nongerminal center b-cell-like than in germinal center b-cell-like phenotype," Cancer, vol. 117, no. 22, pp. 5058-5066, 2011.

[62] C. B. Reeder and S. M. Ansell, "Novel therapeutic agents for Bcell lymphoma: developing rational combinations," Blood, vol. 117, no. 5, pp. 1453-1462, 2011. 


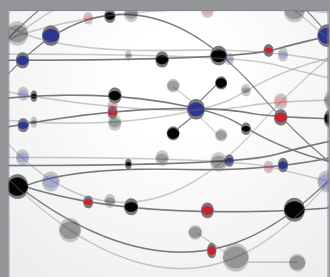

The Scientific World Journal
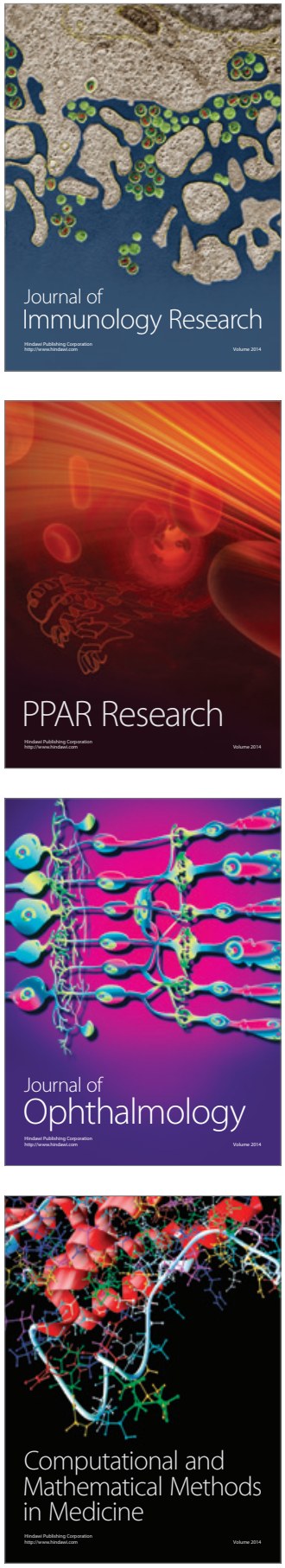

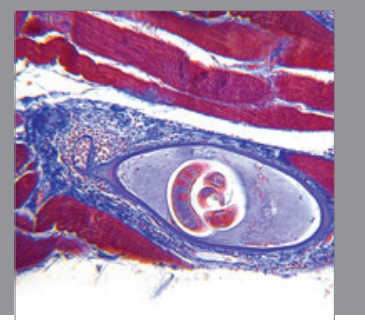

Gastroenterology

Research and Practice
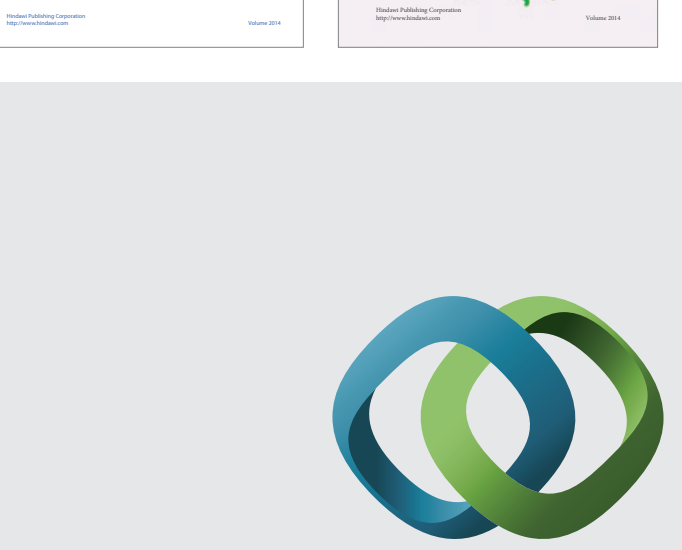

\section{Hindawi}

Submit your manuscripts at

http://www.hindawi.com
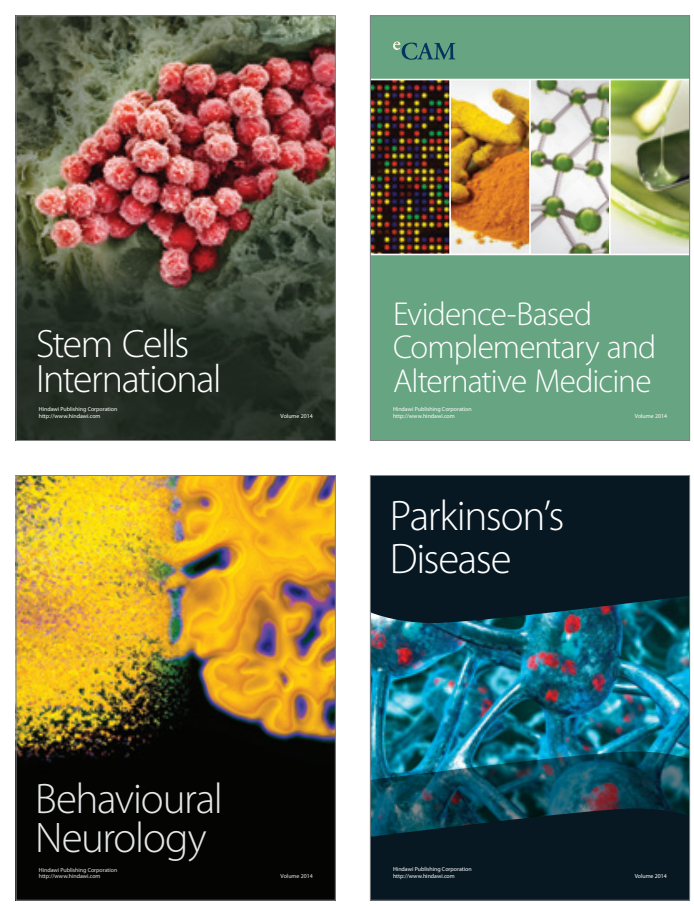

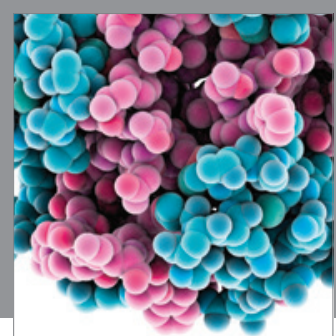

Journal of
Diabetes Research

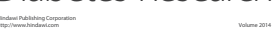

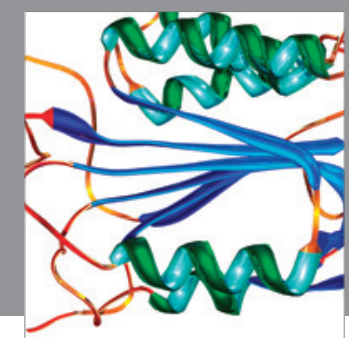

Disease Markers
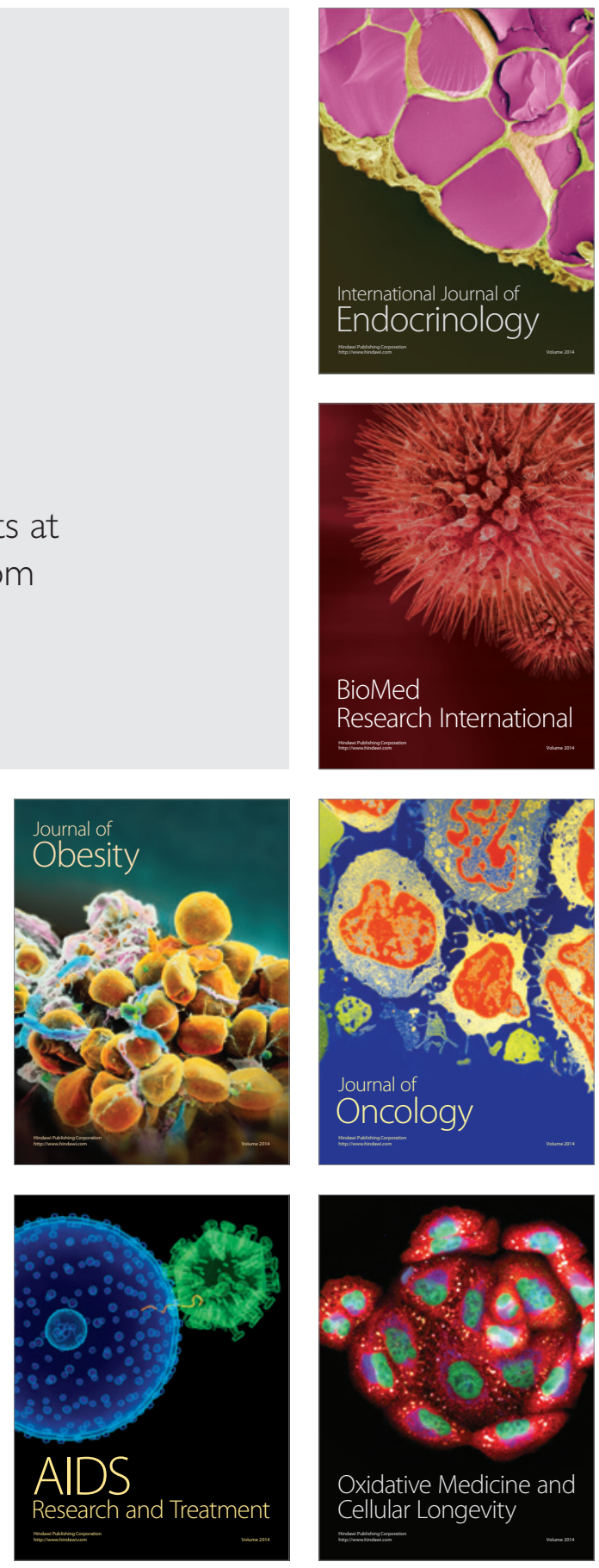